\title{
Review: Effects of fibre, grain starch digestion rate and the ileal brake on voluntary feed intake in pigs
}

\author{
V. Ratanpaul ${ }^{1}$, B. A. Williams ${ }^{1}$, J. L. Black ${ }^{2}$ and M. J. Gidley ${ }^{1 \dagger}$ \\ ${ }^{1}$ Centre for Nutrition and Food Sciences, Queensland Alliance for Agriculture and Food Innovation, The University of Queensland, St Lucia, QLD, 4072, Australia; \\ 2John L Black Consulting, PO Box 4021, Warrimoo, NSW, 2774, Australia
}

(Received 13 January 2019; Accepted 13 May 2019; First published online 21 June 2019)

\begin{abstract}
Grains rich in starch constitute the primary source of energy for both pigs and humans, but there is incomplete understanding of physiological mechanisms that determine the extent of digestion of grain starch in monogastric animals including pigs and humans. Slow digestion of starch to produce glucose in the small intestine (SI) leads to undigested starch escaping to the large intestine where it is fermented to produce short-chain fatty acids. Glucose generated from starch provides more energy than short-chain fatty acids for normal metabolism and growth in monogastrics. While incomplete digestion of starch leads to underutilised feed in pigs and economic losses, it is desirable in human nutrition to maintain consistent body weight in adults. Undigested nutrients reaching the ileum may trigger the ileal brake, and fermentation of undigested nutrients or fibre in the large intestine triggers the colonic brake. These intestinal brakes reduce the passage rate in an attempt to maximise nutrient utilisation, and lead to increased satiety that may reduce feed intake. The three physiological mechanisms that control grain digestion and feed intake are: (1) gastric emptying rate; (2) interplay of grain digestion and passage rate in the SI controlling the activation of the ileal brake; and (3) fermentation of undigested nutrients or fibre in the large intestine activating the colonic brake. Fibre plays an important role in influencing these mechanisms and the extent of their effects. In this review, an account of the physiological mechanisms controlling the passage rate, feed intake and enzymatic digestion of grains is presented: (1) to evaluate the merits of recently developed methods of grain/starch digestion for application purposes; and (2) to identify opportunities for future research to advance our understanding of how the combination of controlled grain digestion and fibre content can be manipulated to physiologically influence satiety and food intake.
\end{abstract}

Keywords: starch, fermentation, ileal/colonic brake, satiety, passage/transit rate

\section{Implications}

Grain/starch digestion rate coefficients show an inverse square dependence on milled grain particle size, providing an opportunity for the pig feed industry to determine optimum particle size distributions for complete digestion in the small intestine to maximise feed utilisation. Mechanistic models based on physiological factors controlling digesta passage rate and feed intake provide a platform for researchers in human and pig nutrition to form testable hypotheses for increasing or decreasing intake by: (1) formulating diets based on grains of different digestibility; and (2) adding fibre of different fermentability at different concentrations.

\section{Introduction}

Cereal grains are usually the main source of dietary energy for monogastric production animals. Feed costs constitute $60 \%$

\footnotetext{
${ }^{\dagger}$ E-mail: m.gidley@uq.edu.au
}

to $70 \%$ of total pork production costs. Digestive utilisation energy varies from $70 \%$ to $90 \%$ for most pig diets, and the rest $(10 \%$ to $30 \%)$ is excreted in urine, faeces, lost as body heat and fermented in the gut and lost as gases (Noblet and Henry, 1993). Therefore, not all of the energy contained in feed grains can be used by animals, depending on feed grain characteristics and physiological limitations of the animal. Maximising energy utilisation for performance and growth is a major aim of the pig production industry. Animal growth and performance are directly dependent on nutrient and feed intake (FI) (Nyachoti et al., 2004; Black et al., 2009). Physiologically, Fl is thought to be, in part, dependent on macronutrient (particularly starch) digestion rate and the consequent passage rate of digesta through the gastrointestinal tract (GIT).

The pig is also a reliable animal model for studying digestion in humans. There are extensive physiological similarities between pigs and humans in the major mechanisms involved in the regulation of feeding behaviour, $\mathrm{Fl}$ and satiety (Roura 
et al., 2016). Although there is a parallel in human and pig digestive physiology and nutrition, in terms of desired outcomes they lie at the opposite end of the spectrum with targets of controlled BW and efficient weight gain, respectively. The aim of this review is to identify the factors affecting starch digestion rate in whole cereal grains, and how dietary fibres affect satiety, passage rate and FI. This understanding can serve as a basis for developing dietary regimes to control and achieve the desired opposite outcomes in humans and pigs (weight maintenance $v$. weight gain) by manipulating satiety and $\mathrm{Fl}$.

\section{Role of starch in pig and human nutrition}

Starch is the major macronutrient in whole-grain diets providing calories for normal energy metabolism in both humans and pigs. Starches from different grains are digested and absorbed at different rates and to different extents, depending on their physicochemical characteristics (Giuberti et al., 2014; Taylor et al., 2015). These physicochemical characteristics of starches can modulate postprandial metabolic response, which potentially affects $\mathrm{Fl}$, nutrient digestibility and hormone release associated with digestion. Starch from grains is digested in the small intestine (SI) to produce glucose. However, a fraction of this starch may escape digestion (resistant starch) and reach the large intestine (LI), where it is fermented, leading to the production of short-chain fatty acids (SCFA) (Lee et al., 2013). The starch converted to glucose in the $\mathrm{SI}$ is more efficient for providing energy to pigs (and humans) compared to SCFA produced as a result of fermentation in the LI (Bosch et al., 2012). Therefore, improving and optimising starch digestion is an important focus of research in monogastric animal production for maximum feed efficiency and live weight gain in pigs.

Recent developments in starch digestion methods (in vitro) The traditional method of classifying starches is based on the assignment of proportions of the starch that are rapidly digested (RDS), slowly digested (SDS) or resistant to digestion (RS) in vitro. This method has the advantage of being straightforward to carry out, but there are a number of drawbacks (Dhital et al., 2017). A recently developed method (Edwards et al., 2014) was based on the realisation that the classification of starches as RDS, SDS and RS can be technically flawed as it does not take into account the digestion kinetics based on changes in the relative concentrations of amylase and starch as the digestion progresses. This method (Edwards et al., 2014) suggests determining the starch digestion rate based on first-order kinetics behaviour of specific grain particle size fractions. However, this limits its usefulness to pig production systems because ground grains in pig (and human) nutrition, as a result of milling and/or mastication, contain a mixture of particle size fractions, and the residence time in the $\mathrm{SI}$ available for digestion varies depending on the transit or passage rate. A recent review (Dhital et al., 2017) of the mechanisms of starch digestion by alpha-amylase suggested that the classification of RS should be based on the interplay of enzyme digestion rate and small intestinal digesta passage rate. Therefore, a robust method is needed to determine the digestibility of ground grains irrespective of particle size, so that a link between in vitro and in vivo grain digestibility can be developed. Particle size is the main determinant of starch digestion rate in milled grains as the digestion by amylase is considered to be a surface-controlled enzyme diffusion process (Al-Rabadi et al., 2009; Mahasukhonthachat et al., 2010). The apparent enzyme (amylase) diffusion rate, based on first-order kinetics analysis of starch digestion in milled grain size fractions, is proposed to be a useful approach to determine intrinsic grain digestibility as it is independent of particle size. Until recently, this had only been determined in a few grain samples (Al-Rabadi et al., 2009; Mahasukhonthachat et al., 2010). However, a recent study (Ratanpaul et al., 2018) showed that plotting the inverse of the first-order digestion rate coefficient against the square of particle size (Figure 1) gave linear plots for all of 16 diverse grain samples, consistent with a surface area-dependent rate-limiting step. The slope of this plot provides the diffusion coefficient for pure diffusion control, but as other surface area-dependent factors cannot be ruled out, we propose to designate this value as an apparent enzyme diffusion coefficient. This coefficient is a measure of the intrinsic digestibility of milled grains (i.e. independent of particle size), and can be used to investigate grain effects on amylase digestibility between species and as a function of growth conditions (Ratanpaul et al., 2018).

\section{Milled grain particle size and digestion rate}

Food structure and particle size have critical roles in determining the rate of small intestinal starch digestion and consequent postprandial metabolism. Characterisation by electron microscopy and solid-state ${ }^{13} \mathrm{C}$ NMR of undigested grain-containing digesta recovered from the ileum of pigs showed that some milled grain particles can escape gastric and SI digestion, maintaining their intact particulate and semi-crystalline structure (Gidley et al., 2011). In contrast, isolated maize starch in the feed results in essentially complete digestion by the midpoint of the SI in pigs (Hasjim et al., 2010). Light microscopy of ileal effluents collected from human ileostomy subjects, $4 \mathrm{~h}$ after consuming cooked wheat porridge (2 $\mathrm{mm}$ particles), showed that some starch granules encapsulated in endosperm cell walls survived digestion in the SI (Edwards et al., 2015). Human ileostomy participants consuming coarse ( $2 \mathrm{~mm}$ particles) wheat porridge showed lower postprandial concentrations of blood glucose and insulin than those consuming smooth $(<2 \mathrm{~mm}$ particles) porridge (Edwards et al., 2015). Smaller particles are digested faster in the SI than larger particles, providing more energy for normal body function and growth. Milled grain particle size has a major impact on starch digestion rate as found from in vitro studies (Al-Rabadi et al., 2009; Mahasukhonthachat et al., 2010; Ratanpaul et al., 2018). Smaller particles lead to a greater extent of growth and feed efficiency in pigs (De Jong et al., 2016; Al-Rabadi et al., 2017). Despite the known effects of milled grain particle size on starch digestion, it is still unknown if the particle size has 

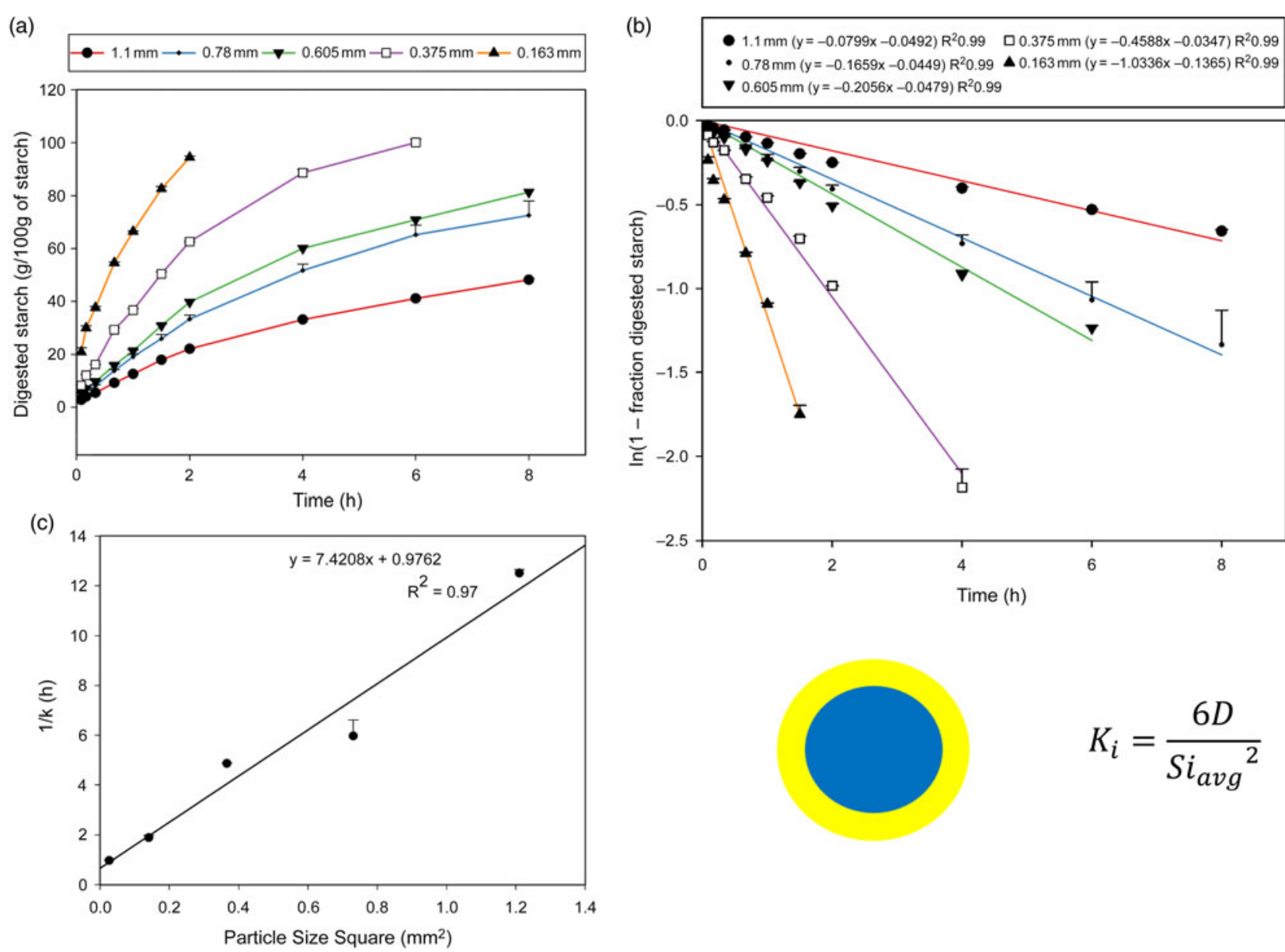

Figure 1 (color online) Starch digestion in vitro for a sorghum sample (Waxy Isoline) with SEM: (a) Digestograms as a function of particle size, (b) first-order kinetics fit - rate coefficient $k\left(\mathrm{~h}^{-1}\right)$ for each fraction is given by the slope, (c) relationship between square of particle size $\left(\mathrm{mm}^{2}\right)$ and inverse of rate coefficient, $1 / k(\mathrm{~h})$ - the slope gives the ADC (Ratanpaul et al., 2018). The fit in (c) shows that the rate constant for digestion (Ki) at a particle size of siavg2 is determined by the diffusion coefficient $\mathrm{D}$. This is consistent with an 'outside-in' surface erosion method of starch digestion from grain particles; the light (yellow) region

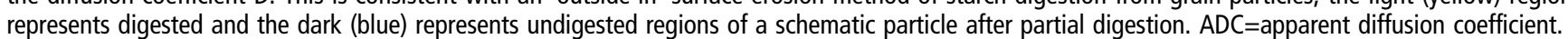

the same effect on starch digestion when the grains are processed (e.g. heat or enzyme treatment) prior to grinding/ milling. Excess BW gain in humans can be a direct result of excess intake of highly digestible foods that provide fast glucose release during digestion (Anderson and Woodend, 2003). Particle size also affects other physiological functions of the gastrointestinal tract such as secretory function (SaquiSalces et al., 2017).

\section{Grain digestion and satiety}

The digestibility of feed and its effects on short-term satiety and FI suggest that two key factors are important: a) the rate of macronutrient (e.g. starch) digestion, which determines the site of digestion in the GIT with slower-digesting nutrients reaching the distal SI or the $\mathrm{Ll}$; and b) feedback control of total FI through modification of satiety through intestinal brakes when digestion is slow. Hormonal and physiological mechanisms involved in this feedback are discussed later, but here we summarise dietary approaches to modifying FI via satiety effects.
The control of FI through modification of satiety is possible with the inclusion of soluble dietary fibre or proteins in the feed consumed (Fiszman and Varela, 2013). In rats, the intake of soluble dietary fibres, such as pectin (Adam et al., 2014) or beta-glucan (Adam et al., 2015), increased, in a dose-dependent manner, postprandial blood concentration of satiety hormones and LI fermentation activity, and decreased Fl, weight gain and adiposity in rats. In humans, soluble dietary fibre is seen as desirable as it slows down the rate of nutrient digestion (Scazzina et al., 2013). In commercial pig production, in terms of feed efficiency, cereal dietary fibres such as beta-glucans and arabinoxylans are considered undesirable due to their negative effects on nutrient digestibility and FI (De Lange, 2000).

\section{Consequences of incomplete starch digestion}

Grains that are highly digestible lead to rapid increases in postprandial blood glucose concentrations and subsequently lead to increased insulin secretion compared to slowerdigested foods (Scazzina et al., 2013). Slow or incomplete 


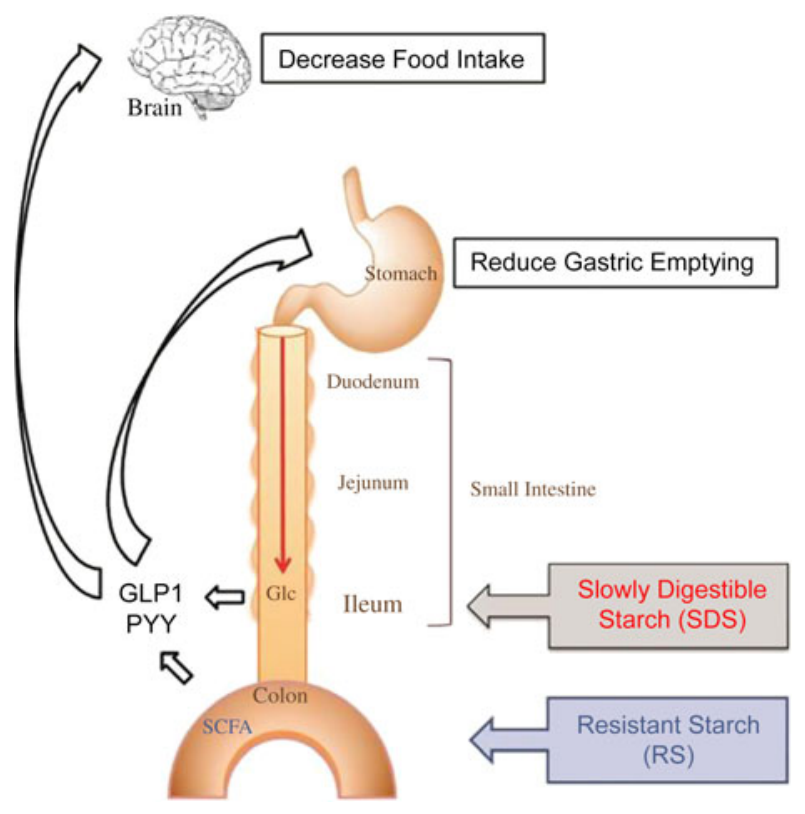

Figure 2 (color online) A schematic to illustrate the effect of ileal and colonic brakes caused by ileal GIc release and SCFA production from colonic fermentation on the rate of passage of digesta and food intake in monogastric animals. Glucagon-like peptide 1 and PYY are released from the ileum and colon, respectively, which control the gastric emptying rate and food intake. Glc=glucose; SCFA=short-chain fatty acids; GLP1=Glucagon-like peptide 1; PYY=peptide YY. Reproduced with permission from Lee et al. (2013).

digestion of starch, proteins and lipids has important consequences (Gidley, 2013) on:

1) insulin secretion, a component of carbohydrate metabolism and also involved in protein digestion, to regulate blood glucose levels. Insulin is the most potent anabolic hormone that facilitates the synthesis and storage of glycogen, lipids and proteins, and inhibits the breakdown and release of these stored macromolecules into the circulation. Insulin also enables the absorption of glucose, amino acids and fatty acids into cells (Saltiel and Kahn, 2001). The overstimulation of this glucose-regulating hormonal mechanism, over time, can lead to increased risk of type II diabetes;

2) ileal brake activation that takes place when digestion is slow and more nutrient uptake occurs towards the end of the $\mathrm{SI}$, that is, the ileum (Maljaars et al., 2008); and

3) fermentation in the LI that occurs when starch and/or dietary fibre escapes gastric and SI digestion. Undigested and fermentable carbohydrates reaching the $\mathrm{LI}$ are fermented to produce SCFA. These SCFA are chemosensed by the FFAR2 receptor in the colon, leading to the secretion of appetite-suppressing gut peptide (PYY), reducing $\mathrm{FI}$ (Brooks et al., 2017). PYY has been implicated in reducing the gastric emptying rate (GER) as shown by a comparative study (Nightingale et al., 1996) in human subjects with and without a colon. Human subjects with a colon had a higher colonic concentration of PYY and reduced GER after consuming pancakes and orange juice; and this effect was referred to as the 'colonic brake' (Nightingale et al., 1996). A recent study (Chambers et al., 2015) involving the delivery of inulin-propionate ester to the colon in human subjects showed that propionic acid promoted postprandial secretion of PYY and GLP-1 and reduced energy intake.
Of the various SCFA produced as a result of colonic fermentation of dietary fibre, propionic acid has the highest affinity for FFAR2 (Chambers et al., 2015), a trigger for gut peptide secretion. In an experiment in pigs, a decreased insulin secretion after the consumption of rye bread was found to be associated with a higher absorption of butyrate generated by bacterial fermentation in the LI (Theil et al., 2011). These findings highlight the importance of colonic fermentation and its end-products in influencing the effectiveness of satiety hormones. Both ileal and colonic brakes reduce the passage rate of digesta and FI (Black et al., 2009; Lee et al., 2013).

\section{Physiological factors affecting the rate of passage and feed intake}

A wide array of factors affect $\mathrm{Fl}$ in humans (Rolls, 2007) and pigs (Nyachoti et al., 2004; da Silva et al., 2012). In pigs, the main factors affecting $\mathrm{Fl}$ are: (1) environmental factors: temperature, humidity and ventilation; (2) social factors: space allocation, feeder space, group size in pens, familiarity with other pigs and regrouping; (3) animal factors: health status, age, gender, physiological status and genetic effects; and (4) dietary factors: feed bulk and physical FI capacity, nutrient intake levels, dietary nutrient content and balance, feed additives, dietary contaminants, feed processing and ingredient type, feed form and presentation and availability of drinking water. In commercial pig production, all of these factors act together to affect Fl. Although many of these factors have been studied individually, and their effect on FI quantified, the combined effect of all these factors is not well understood (Nyachoti et al., 2004). The focus here is to cover only those animal and dietary factors that physiologically affect the digestive processes and hence influence Fl. Feed intake is likely to be controlled by two main physiological and biochemical processes: (1) rate of passage of digesta or transit time through the GIT (Black et al., 2009), and (2) activation of satiety and hunger centres in the brain as a result of meal consumption, absorption of digested nutrients and metabolite generation from subsequent biochemical processes (Nyachoti et al., 2004; Black et al., 2009).

\section{Rate of passage of digesta as influenced by gastric emptying rate, and ileal and colonic brakes} Various studies of different monogastric animals, including pigs (Phillips et al., 1982), have suggested that $\mathrm{Fl}$ is inversely related to transit time of digesta through the GIT (Black et al., 2009). However, the physiological mechanisms controlling FI through the rate of passage of digesta are not yet fully understood. A simplified schematic (Figure 2) of the monogastric GIT illustrates the effect of ileal and colonic brakes on the rate of digesta passage and FI.

\section{Gastric distension and emptying rate}

The stomach acts as a 'holding tank' for ingested feed and controls the flow of digesta through the pylorus to the duodenum. Therefore, gastric distension and emptying rate influence the rate of passage or transit time of digesta through the upper GIT. The presence of feed in the stomach causes initial 


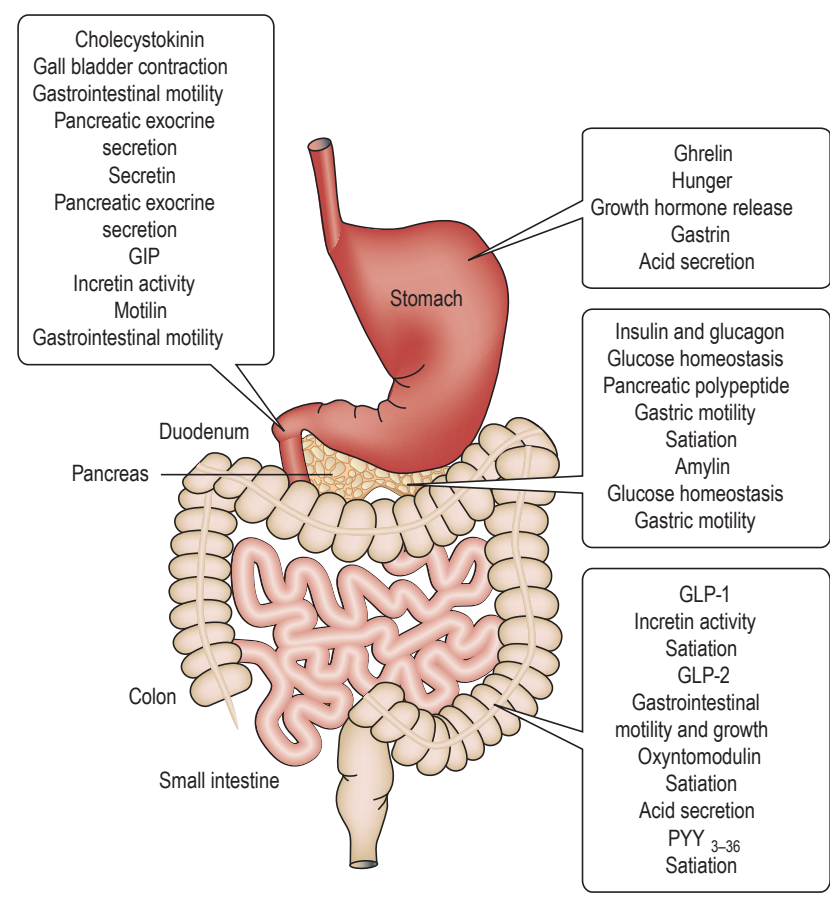

Figure 3 (Colour online) A schematic of the gastrointestinal tract in monogastric animals illustrating the sites where gut hormones are released and their major putative functions. GIT=gastrointestinal tract; GIP=gastric inhibitory polypeptide; $G L P=$ glucagon-like peptide; $P Y Y=$ peptide YY. Reproduced with permission from Murphy and Bloom (2006).

distal gastric contractions and gastric emptying through the pyloric valve, which depends on the volume and subsequent gastric distension. Hence, an initial increase in the rate of passage is caused by volume effects rather than by nutrients (Black et al., 2009). Gastric distension caused by an increasing volume of food has the effect of sending satiety signals via the vagal nerve to the brain with a consequent reduced $\mathrm{FI}$ (Maljaars et al., 2007). However, the effects of gastric volume on satiety are only short-term and meal-related. While gastric satiety is largely volumetric, intestinal (duodenal) satiety is nutritional. Nutritional satiety signals act in synergy with gastric volumetric signals in controlling the GER (Powley and Phillips, 2004; Cummings and Overduin, 2007).

\section{Role of starch digestion rate, grain particle size and intact tissue structure}

The presence of intact cellular structures from cereal-based foods inaccessible to mammalian amylases decreases the starch digestion rate (Scazzina et al., 2013). Proteins can delay gastric emptying, though results have not always been consistent. Large grain particles delay gastric emptying in pigs as shown by barley ground through a $4.68-\mathrm{mm}$ screen compared with a 1.56-mm one (Potkins et al., 1991). Retropulsion and forceful grinding of large particles in the gastric antrum (Brown et al., 1993; Schulze, 2006) reduces the particle size before passage through the pylorus is possible.

The activation of ileal brake, as a result of undigested nutrients in the ileum, through mediators such as PYY,
GLP-1 and vagal nerve stimulation (Maljaars et al., 2008) leads to a reduction in hunger and $\mathrm{Fl}$. The authors (Maljaars et al., 2008) argue that after ileal brake activation, enhanced gastric distension from delayed gastric emptying is most likely the cause of stimulation of satiety centres in the brain through hormonal and neural signals, which in turn lead to a reduction in hunger and $\mathrm{Fl}$. Several studies have indicated that SCFA in the ileum inhibit gastric motility and subsequently slow gastric emptying (Cherbut et al., 1997). Short-chain fatty acids reaching the ileum from the colon as a result of colo-ileal reflux also inhibit gastric motility in pigs by a humoral pathway in which PYY is released (Cuche et al., 2000). Apart from lipids, ileal infusion of sucrose and casein also reduces $\mathrm{Fl}$ in humans; and a reduction in GER and intestinal transit rate was observed concomitant with an increased concentration of cholecystokinin and PYY in the ileum, indicating the activation of the ileal brake (van Avesaat et al., 2015). There is no available data other than ileal infusion of isolated nutrients (Maljaars et al., 2007; Maljaars et al., 2008; van Avesaat et al., 2015) on the effects of ileal brake activation in humans.

A review (Black et al., 2009) explained that colonic fermentation of undigested carbohydrates and subsequent SCFA production induces a colonic brake, which reduces the passage rate of digesta, increases oesophageal sphincter tension, lowers gastric tone, decreases GER, reduces gastric and pancreatic secretions and reduces intestinal motility. The result of these effects of colonic brake is a slower passage of digesta through the GIT and reduced FI. The presence of nutrients in the distal ileum and colon, rather than in the proximal regions, has greater effects in decreasing GER and transit time through the SI, which consequently reduces $\mathrm{FI}$.

It is apparent that there is more direct evidence of the colonic brake (Nightingale et al., 1996) than the ileal brake. Ideally, a direct measure of gastric and SI passage rates based on grains with widely varying digestibility would verify whether the undigested nutrients indeed reduce passage rate by triggering ileal and colonic brakes, without ileal or colonic infusion of nutrients or SCFA.

\section{Hormonal control of feed intake}

There are more than 20 different regulatory peptide hormones secreted by the GIT (Figure 3), the largest endocrine organ in the body. These hormones are released in response to the presence of nutrients in the gut and carry signals to the brain regarding the current energy balance. Most of these hormones are sensitive to the availability of nutrients in the GIT, and short-term feelings of hunger and satiety are consequences of their changing circulating levels (Murphy and Bloom, 2006). Gut hormones and the adipose hormone leptin reduce $\mathrm{FI}$, whereas ghrelin is the only peptide hormone secreted in the stomach, and increases appetite and induces feelings of hunger. Circulating ghrelin levels fall after a meal and increase on fasting (Murphy and Bloom, 2006). Longterm energy homeostasis is regulated by circulating levels of insulin and leptin in proportion to recent nutrient intake 
and body adiposity. The short- and long-term energymaintaining mechanisms work collaboratively such that insulin and leptin seem to determine the brain sensitivity to satiety, inducing effects of short-term peptide signals from the GIT (Havel, 2001).

In humans, low GI foods reduce postprandial blood glucose and plasma insulin levels, stimulate gastric inhibitory polypeptide (GIP) secretions and exert a second meal effect of low postprandial glucose upon consumption of high $\mathrm{Gl}$ foods (Jenkins et al., 1982). The second meal effect is the blood glucose-lowering effect that a first meal has on the blood glucose level after consumption of a subsequent meal (Jenkins et al., 1982). Carbohydrates in the upper GIT stimulate GIP release, and a reduction in GIP response indicates a decreased concentration of sugars available for absorption (Jenkins et al., 1982). Slower gastric emptying (Lee et al., 2013) after consumption of the second meal suggests that SCFA are involved in gastric motility. Slower gastric emptying directly reduces $\mathrm{Fl}$.

Interactions between starch digestion rate and feed intake The interactions between macronutrient (particularly starch) digestion rate and $\mathrm{FI}$ in monogastric animals may offer opportunities to improve growth performance and economic benefits for the animal industry by manipulating satiety and $\mathrm{FI}$ for efficient feed utilisation and growth. This scenario runs in parallel for human nutrition, but in the opposite direction, where satiety can be manipulated by meal composition to regulate healthy BW and prevent or alleviate obesity.

Therapeutic drugs to control obesity do not target natural physiological satiety mechanisms and can have side effects. Mimicking natural satiety mechanisms by administering a combination of gut hormones may provide effective antiobesity treatment (Wren and Bloom, 2007). The challenge is that the GIT is a complex organ with many hormones secreted from different locations in response to the presence of nutrients in a precise manner, which is difficult to mimic. The ability to control or manipulate the rate of passage of digesta may provide a natural way to induce and control satiation and satiety without having to administer gut hormones exogenously. Signals of satiation (the feeling of fullness) and satiety (the postprandial prevention of hunger onset) originate primarily from gastric distension and nutrient sensing in the intestine, respectively, activating neural and humoral pathways (Powley and Phillips, 2004; Cummings and Overduin, 2007). Prolonged ileal brake activation, as demonstrated by ileal intubation and surgical studies, can lead to major weight loss in humans by reduction in hunger and FI impacting BW regulation (Maljaars et al., 2007). In contrast, ileal brake activation is expected to have negative effects on animal performance as it reduces $\mathrm{Fl}$, but is a relatively unexplored territory in monogastric animal nutrition. Finding ways to avoid ileal brake activation from intake of feed ingredients with defined digestibility is, therefore, an attractive target in order to maximise growth performance in pigs.
Ileal infusion of glucose in human subjects has shown enhancement of satiety and reduced energy intake (Shin et al., 2013). As both ileal and colonic brakes induce satiety and reduce FI (Shin et al., 2013), in order to alleviate obesity in humans, one approach is to structure starchy foods made from cereals so they can reach the ileum and colon undigested (Taylor et al., 2015). In humans, insoluble fibre, from a source such as wheat bran, has been used to treat constipation (Muir et al., 2004), but has not been given much consideration as a tool for manipulating satiety in combination with other nutrients by virtue of its ability to stimulate the passage rate.

Physiological effects of fibre in the gastrointestinal tract in relation to starch digestion rate and feed intake

A number of studies (Livesey and Tagami, 2009; Scazzina et al., 2013) have supported the concept that soluble fibre that increases viscosity of digesta results in a low glycaemic response upon consumption of foods containing starch, due to slow GER and absorption of nutrients in the SI. The underlying mechanism is proposed to be inhibition of enzyme access to digesta in the stomach and SI. From a meta-analysis (Livesey and Tagami, 2009), it has been proposed that soluble fibres which are non-viscous, such as resistant maltodextrin, can also attenuate glycaemic response when added to drinks and consumed with starchy foods. Some of the mechanisms suggested are slower GER, quicker transit of digesta to the distal SI where absorption may be less rapid and inhibition of digestive enzymes. The mixing of digesta in the stomach and SI increases the probability of enzyme-substrate binding, whereas viscosity of the fluid without any mixing hinders the enzyme-substrate complex formation required for digestion (Dhital et al., 2014), as is the case for grain particle size effects (Figure 1).

The effects of dietary fibre on GER and rate of passage in the GIT are related to the volume and physical properties of gastric and intestinal contents. The GER is also controlled by biological feedback mechanisms operating in the SI through receptors sensitive to osmolality, acidity and particle size of the digesta (Potkins et al., 1991). Wheat bran included in diets of humans (Lewis and Heaton, 1997) or pigs (Wilfart et al., 2007) reduced whole gut transit time. In a study with different soluble and insoluble fibres added to diets offered to human subjects, wheat bran showed the most potent effect of increasing the rate of passage, while soluble fibres showed the opposite effect (Jenkins et al., 1978). Pigs fed diets containing neutral detergent fibre (NDF) from different sources showed increased rate of passage through the GIT with increasing NDF levels (Stanogias and Pearcet, 1985).

In pigs fed ad libitum, FI increases sufficiently with decreasing digestible energy content from addition of fibre, to maintain normal metabolism and homeostasis. This increase in FI occurs with increasing GIT capacity and changes the transit time of digesta. Eventually, a threshold point is reached beyond which the FI cannot be increased any further by additional fibre to compensate for the declining energy density. At that point, the energy intake required for normal metabolism falls (Black, 2000). At high fibre 
concentrations, the hydration and swelling capacity of pig feeds increases. The reduction in energy density and increase in feed bulk and digesta swelling in the stomach causes gastric distension and reduces Fl in pigs (Kyriazakis and Emmans, 1995; Brachet et al., 2015). In humans with a different eating behaviour to pigs, postprandial gastric distension contributes to satiation in synergy with pre- and post-gastric nutrient stimuli as the volume of meals is not sufficient to cause excessive gastric distension (Ritter, 2004; Cummings and Overduin, 2007).

A recent review (Capuano, 2017) on the physiological effects of dietary fibre in the human GIT highlights that there is much information on the physiological effects of soluble and fermentable fibre in the mouth, stomach, SI and LI. Both soluble and insoluble fibre can increase transit rate through the $\mathrm{SI}$ and $\mathrm{LI}$ to variable extents because of the enhanced effect of peristalsis on digesta with increased bulk and swelling through water absorption. The effects of fibre (soluble or insoluble) on the transit rate are well studied for the LI, whereas limited information is available for the effects of fibre on the transit rate in the SI (Wilfart et al., 2007; Capuano, 2017), where digestion of most macronutrients takes place. Passage rate in the $\mathrm{SI}$ determines the extent and site of digestion (Lee et al., 2013), and therefore the interplay of digestion rate and passage rate in the $\mathrm{SI}$ as influenced by fibre needs to be explored.

The rate of passage of digesta is a critical physiological factor that determines FI through the GIT and rate of digestion. During the postprandial period, peptides released from the stomach and duodenum, and mild distension of the GIT, stimulate the rate of passage (Black et al., 2009). As undigested nutrients trigger ileal and colonic brakes (Black et al., 2009; Lee et al., 2013), a decline in passage rate increases the extent of digestion by increasing the time available for enzymatic digestion in the $\mathrm{SI}$, but also reduces $\mathrm{FI}$ through delayed gastric emptying. The negative effect of ileal brake on FI may be compensated for by inclusion of higher amounts of indigestible fibre in the diet to increase $\mathrm{Fl}$ by stimulating the passage rate (Campbell, 1988; Black et al., 2009).

An evaluation (Vicente et al., 2008) of the effects of feeding cooked corn and cooked rice to pigs showed that the pigs (from 25 until 53 days of age) fed cooked rice had $23 \%$ higher $\mathrm{Fl}, 29 \%$ faster growth rate and $5 \%$ more efficient feed conversion ratio than pigs fed cooked corn only. A similar experiment (Mateos et al., 2006) investigated the effects of cooked maize and cooked rice with addition of cooked and expanded oat hulls at levels of 20 and $40 \mathrm{~g} / \mathrm{kg}$ in the diet on productive performance of piglets weaned at 21 days till 54 days of age. Addition of oat hulls reduced $\mathrm{Fl}$ and average daily weight gain in pigs fed diets based on maize, but increased both $\mathrm{FI}$ and average daily weight gain for diets based on rice. This may be due to higher indigestible fibre levels increasing the rate of digesta passage, leading to more undigested maize starch ending up in the distal intestine and activating the ileal brake. On the other hand, more highly digestible rice starch would have little chance to escape digestion in the SI and reach the distal intestine even with an increased passage rate, and therefore would not be able to activate the ileal brake (Black et al., 2009). Another study (Gerritsen et al., 2012) on 28-day-old piglets found that the addition of $15 \%$ indigestible fibre consisting of oat hulls and wheat straw to a normal cereal diet $(25 \%$ barley, $20 \%$ wheat and $20 \%$ corn) increased $\mathrm{Fl}$ and weight gain in piglets during the first 14-day post-weaning period.

A critical evaluation of the findings of the aforementioned studies implies that indigestible fibre can: (1) increase the negative effect of slowly digestible cereal grain fractions on Fl, by activating the ileal brake sooner, and (2) enhance Fl of highly digestible cereal grain fractions by stimulating the passage rate of digesta and maximising digestion before the ileal brake has a chance to act, since most nutrients are digested before reaching the ileum.

The effects of fibre on the GIT passage rate in pigs have been investigated (Jorgensen et al., 1997; Wilfart et al., 2007; da Silva et al., 2012). However, it is difficult to compare the findings, as these were based on diets containing different grains and fibres. In addition, the indigestible markers used to determine passage rates were also mostly different. It becomes complicated to interpret results across different studies when different experimental strategies and feeding regimes are used. Moreover, no attempts seem to have been made to investigate whether macronutrient digestion rates influence passage rate.

Fibre, both soluble and insoluble, increases passage rate through the $\mathrm{SI}$ and LI. A higher $(268 \mathrm{~g} / \mathrm{kg})$ proportion of dietary fibre (pea fibre and pectin) fed to pigs increased the passage rate, measured at the end of ileum, by five to six times compared with low-fibre diets $(59 \mathrm{~g} / \mathrm{kg})$, and this was attributed to the water-holding capacity of the dietary fibre used in the diets (Jorgensen et al., 1997). An important study (Wilfart et al., 2007) with double proximal duodenal and distal ileal cannulation of pigs investigated the effects of insoluble fibre from wheat bran $(0 \%, 20 \%$ and $40 \%)$ on mean retention time in different segments of the GIT of pigs $(\sim 33 \mathrm{~kg})$ and reported that mean retention time in the stomach, SI and LI was 1, 4, and 38 h, respectively. Higher insoluble fibre content reduced mean retention time of both solid and liquid phases in both the SI and LI, but had no effect on the GER. However, MRT of the liquid phase in the $\mathrm{LI}$ was 4 to $8 \mathrm{~h}$ less than that of the solid phase. A major limitation of the study was that pigs were fed six equal rations at 4-h intervals on the day of digesta collection, and individual meal size might not have been sufficient to fill the stomach and cause any gastric distension. This could explain their finding that despite the high level of wheat bran up to $40 \%$ in the diet, there was no effect on GER.

Transit time also depends on the length of the intestinal tract, which increases with age. Mean retention time through the GIT, nutrient and fibre digestibility all increase with the age of pigs (Le Goff et al., 2002; Kim et al., 2007), as longer retention time improves nutrient digestibility. A study (SolàOriol et al., 2010) investigating the effect of wheat bran $(13 \%)$ offered to pigs with white rice or oats found a faster passage rate for oats. The authors concluded that cereal with 
high fibre content, such as oats, increased passage rate. However, the authors did not characterise grain digestibility or measure ileal digestibility of nutrients. The diets (SolàOriol et al., 2010) contained $60 \%$ grains (rice or oats), wheat bran $(13 \%)$ and soybean meal (20\%). Grains are (partially) digested in the SI depending on the particle size and intrinsic grain digestibility. Undigested grains reaching the LI may ferment and reduce the passage rate by triggering colonic brake, as discussed earlier. Wheat bran and soybean meal are also at least partially fermentable. It is important to consider individual ingredient fermentability before formulating diets intended for passage rate studies.

Another challenge is that passage rate studies (Albin et al., 2001; Solà-Oriol et al., 2010) are usually based on rationed rather than ad libitum feeding. This approach may not allow true manifestation of physiological mechanisms controlling passage rate and $\mathrm{Fl}$, as $\mathrm{Fl}$ also depends on satiety signals arising from the stomach (Powley and Phillips, 2004; Cummings and Overduin, 2007). Ad libitum feeding eliminates external controls that stop pigs from eating while pigs may be hungry between rationed meals.

In an ad libitum study (Adam et al., 2014), rats were fed $5 \%$ cellulose and $10 \%$ of either cellulose, fructo-oligosaccharides, oat beta-glucan or apple pectin added to their normal diets. It was found that rats on a diet with $10 \%$ cellulose had the highest cumulative $\mathrm{Fl}$ followed closely by the $5 \%$ cellulose diet. Fl and weight gain was significantly higher in rats on cellulose diets than on soluble fibre diets. Insoluble fibres from different sources have different functional effects in the gut. Wheat bran increased the rate of passage of digesta in pigs (Stanogias and Pearcet, 1985; Wilfart et al., 2007), and can also shift the site of fermentation of indigestible carbohydrates from caecum and proximal to distal colon (Govers et al., 1999). In an investigation in humans it was found that wheat bran increased digesta transit rate, and coarse bran was more effective at increasing transit rate than finely ground bran (Heller et al., 1980). Two investigations (Mateos et al., 2006; Gerritsen et al., 2012) have implicated oat hulls as a promising source of indigestible fibre, which perhaps could be used to increase passage rate and $\mathrm{FI}$ to derive maximum performance in pigs. Due to the positive effects, though slight, of pelleting high-fibre diets on nutrient digestibility, the dietary fibre content in pig diets is expected to increase in the near future (Le Gall et al., 2009). Therefore, the effects of high-fibre diets on $\mathrm{Fl}$ and growth performance deserve new studies with different fibre sources.

\section{Conclusions and gaps in current knowledge}

- Macronutrient (e.g. starch) digestion rate determines the site of digestion throughout the GIT, together with the digesta passage rate. Starch is the major nutrient that provides energy for metabolism, energy homeostasis and growth. The enzyme diffusion rate of milled grain particles is the main determinant of the digestion rate of starch and, in part, determines the site of digestion in the GIT. To understand the mechanistic cause-and-effect relationships between digestion behaviour and these benefits over time, there is a need to understand diffusion behaviour of amylolytic enzymes, digestion kinetics of starch and release of glucose from whole grains. Knowing the proportion of starch fermented in the LI allows calculation of the proportion of starch energy not available for metabolism because of heat of fermentation, methane, lower use of SCFA than glucose and microbes/microbial products excreted in faeces.

- Dietary fibre, both soluble and insoluble, affects the digestion of macronutrients (starch, proteins and lipids). Both soluble and insoluble fibres increase passage rate through the SI and LI. However, there is less information on the rate of passage in the SI compared with the LI. Partially or undigested nutrients reaching the distal SI trigger ileal and colonic brakes, and are expected to induce satiety by neural and humoral mechanisms leading to reduced FI. The effects of the interplay of macronutrient digestion rate and passage rate in the SI have not been investigated in relation to the effects on Fl. Fibre has the potential to influence the site of digestion of macronutrients in the $\mathrm{SI}$, by virtue of its effects on passage rate. The prevalence of cereal grains in human and pig nutrition, and a need for increased use of fibre in their diets, provides a compelling reason to investigate and understand the interactions of grain digestion rate and fibre, and their effects on passage rate in relation to $\mathrm{FI}$.

- Many studies on passage rate in pigs are based on rationed feeding. In order to eliminate the external control of Fl, it is important to investigate $\mathrm{Fl}$ in relation to passage rate based on ad libitum feeding. This will allow assessment of satiety and under which conditions FI may be reduced.

- There is limited information on insoluble and non-fermentable fibres originating from sources such as cereal hulls, in relation to GIT passage rate. Evidence of the effects of (partly fermentable) wheat bran on passage rate supports the idea that insoluble fibres can influence passage rate. A next step is to investigate if largely insoluble and non-fermentable fibre can be added to grain-based diets to achieve a desired change in the passage rate to manipulate satiety.

\section{Acknowledgements}

Funding was provided by the Pork Co-operative Research Centre and the Australian Research Council Centre of Excellence in Plant Cell Walls (CE110001007).

(1) Michael Gidley, 0000-0002-8372-4527

\section{Declaration of interest}

None.

\section{Ethics statement}

No approval by an ethics committee was required for this review.

\section{Software and data repository resources}

None of the data were deposited in an official repository. 


\section{References}

Adam CL, Williams PA, Dalby MJ, Garden K, Thomson LM, Richardson AJ, Gratz SW and Ross AW 2014. Different types of soluble fermentable dietary fibre decrease food intake, body weight gain and adiposity in young adult male rats. Nutrition \& Metabolism 11, 1-12.

Adam CL, Williams PA, Garden KE, Thomson LM and Ross AW 2015. Dosedependent effects of a soluble dietary fibre (pectin) on food intake, adiposity, gut hypertrophy and gut satiety hormone secretion in rats. PloS One 10, e0115438. Albin DM, Wubben JE, Smiricky MR and Gabert VM 2001. The effect of feed intake on ileal rate of passage and apparent amino acid digestibility determined with or without correction factors in pigs. Journal of Animal Science 79, 1250-1258.

Al-Rabadi GJ, Gilbert RG and Gidley MJ 2009. Effect of particle size on kinetics of starch digestion in milled barley and sorghum grains by porcine alpha-amylase. Journal of Cereal Science 50, 198-204.

Al-Rabadi GJ, Hosking BJ, Torley PJ, Williams B, Bryden WL, Nielsen SG, Black JL and Gidley MJ 2017. Regrinding large particles from milled grains improves growth performance of pigs. Animal Feed Science and Technology 233, 53-63.

Anderson GH and Woodend D 2003. Consumption of sugars and the regulation of short-term satiety and food intake. The American Journal of Clinical Nutrition 78, 8435-849S.

Black JL 2000. Amino acid and energy requirements. In Feed evaluation: principles and practice (ed. PJ Moughan, MWA Verstegen and MI Visser-Reyneveld), pp. 189-207. Wageningen Press, Wageningen, Netherlands.

Black JL, Williams BA and Gidley MJ 2009. Metabolic regulation of feed intake in monogastric mammals. In Voluntary feed intake in pigs. (ed. D Torrallardona and E Roura), pp. 189-213. Wageningen Academic Publishers, Wageningen, The Netherlands.

Bosch MW, Borne VDJJGC and Gerrits WJJ 2012. Quantifying resistant starch using novel, in vivo methodology and the energetic utilization of fermented starch in pigs. The Journal of Nutrition 142, 238-244.

Brachet M, Arroyo J, Bannelier C, Cazals A and Fortun-Lamothe L 2015 Hydration capacity: a new criterion for feed formulation. Animal Feed Science and Technology 209, 174-185.

Brooks L, Viardot A, Tsakmaki A, Stolarczyk E, Howard JK, Cani PD, Everard A, Sleeth ML, Psichas A, Anastasovskaj J, Bell JD, Bell-Anderson K, Mackay CR, Ghatei MA, Bloom SR, Frost G and Bewick GA 2017. Fermentable carbohydrate stimulates FFAR2-dependent colonic PYY cell expansion to increase satiety. Molecular Metabolism 6, 48-60.

Brown BP, Schulze-Delrieu K, Schrier JE and Abu-Yousef MM 1993. The configuration of the human gastroduodenal junction in the separate emptying of liquids and solids. Gastroenterology 105, 433-440.

Campbell RG 1988. Nutritional constraints to lean tissue accretion in farm animals. Nutrition Research Reviews 1, 233-253.

Capuano E 2017. The behavior of dietary fiber in the gastrointestinal tract determines its physiological effect. Critical Reviews in Food Science and Nutrition 57, 3543-3564.

Chambers ES, Viardot A, Psichas A, Morrison DJ, Murphy KG, Zac-Varghese SEK, MacDougall K, Preston T, Tedford C, Finlayson GS, Blundell JE, Bell JD, Thomas EL, Mt-Isa S, Ashby D, Gibson GR, Kolida S, Dhillo WS, Bloom SR, Morley W, Clegg $S$ and Frost $G$ 2015. Effects of targeted delivery of propionate to the human colon on appetite regulation, body weight maintenance and adiposity in overweight adults. Gut 64, 1744-1754.

Cherbut C, Aube A, Blottiere H and Galmiche J 1997. Effects of short-chain fatty acids on gastrointestinal motility. Scandinavian Journal of Gastroenterology 32, 58-61.

Cuche G, Cuber J and Malbert C-H 2000. Ileal short-chain fatty acids inhibit gastric motility by a humoral pathway. American Journal of PhysiologyGastrointestinal and Liver Physiology 279, G925-G930.

Cummings DE and Overduin J 2007. Gastrointestinal regulation of food intake. The Journal of Clinical Investigation 117, 13-23.

da Silva CS, van den Borne JJGC, Gerrits WJJ, Kemp B and Bolhuis JE 2012. Effects of dietary fibers with different physicochemical properties on feeding motivation in adult female pigs. Physiology \& Behaviour 107, 218-230.

De Jong JA, DeRouchey JM, Tokach MD, Dritz SS, Goodband RD, Paulk CB, Woodworth JC, Jones CK and Stark CR 2016. Effects of wheat source and particle size in meal and pelleted diets on finishing pig growth performance, carcass characteristics, and nutrient digestibility. Journal of Animal Science 94 3303-3311.

De Lange CFM 2000. Characterisation of the non-starch polysaccharides. In Feed evaluation: principles and practice (ed. P Moughan, $M$ Verstegen and $M$ VisserReyneveld), pp. 77-92. Wageningen Press, Wageningen, The Netherlands.

Dhital S, Dolan G, Stokes JR and Gidley MJ 2014. Enzymatic hydrolysis of starch in the presence of cereal soluble fibre polysaccharides. Food \& Function 5 , 579-586.

Dhital S, Warren FJ, Butterworth PJ, Ellis PR and Gidley MJ 2017. Mechanisms of starch digestion by alpha-amylase-Structural basis for kinetic properties. Critical Reviews in Food Science and Nutrition 57, 875-892.

Edwards CH, Grundy MML, Grassby T, Vasilopoulou D, Frost GS, Butterworth PJ, Berry SEE, Sanderson J and Ellis PR 2015. Manipulation of starch bioaccessibility in wheat endosperm to regulate starch digestion, postprandial glycemia, insulinemia, and gut hormone responses: a randomized controlled trial in healthy ileostomy participants. American Journal of Clinical Nutrition 102, 791-800.

Edwards $\mathrm{CH}$, Grundy MML, Warren FJ, Milligan PJ, Butterworth PJ and Ellis PR 2014. A novel method for classifying starch digestion by modelling the amylolysis of plant foods using first-order enzyme kinetic principles. Food \& Function 5 , 2751-2758.

Fiszman S and Varela P 2013. The satiating mechanisms of major food constituents - an aid to rational food design. Trends in Food Science \& Technology 32 43-50.

Gerritsen R, van der Aar P and Molist F 2012. Insoluble nonstarch polysaccharides in diets for weaned piglets. Journal of Animal Science 90, 318-320.

Gidley MJ 2013. Hydrocolloids in the digestive tract and related health implications. Current Opinion in Colloid \& Interface Science 18, 371-378.

Gidley MJ, Flanagan BM, Sharpe K and Sopade PA 2011. Starch digestion in monogastrics-mechanisms and opportunities. Recent Advances in Animal Nutrition - Australia 18, 207-213.

Giuberti G, Gallo A, Masoero F, Ferraretto LF, Hoffman PC and Shaver RD 2014. Factors affecting starch utilization in large animal food production system: a review. Starch/Staerke 66, 72-90.

Govers M, Gannon NJ, Dunshea FR, Gibson PR and Muir JG 1999. Wheat bran affects the site of fermentation of resistant starch and luminal indexes related to colon cancer risk: a study in pigs. Gut 45, 840-847.

Hasjim J, Lavau GC, Gidley MJ and Gilbert RG 2010. In vivo and in vitro starch digestion: are current in vitro techniques adequate? Biomacromolecules 11, 3600-3608.

Havel PJ 2001. Peripheral signals conveying metabolic information to the brain: short-term and long-term regulation of food intake and energy homeostasis. Experimental Biology and Medicine 226, 963-977.

Heller S, Hackler L, Rivers J, Van Soest P, Roe D, Lewis B and Robertson J 1980. Dietary fiber: the effect of particle size of wheat bran on colonic function in young adult men. American Journal of Clinical Nutrition 33, 1734-1744.

Jenkins D, Wolever T, Leeds AR, Gassull MA, Haisman P, Dilawari J, Goff DV, Metz GL and Alberti K 1978. Dietary fibres, fibre analogues, and glucose tolerance: importance of viscosity. British Medical Journal 1, 1392-1394.

Jenkins D, Wolever T, Taylor RH, Griffiths C, Krzeminska K, Lawrie J, Bennett C, Goff DV, Sarson DL and Bloom S 1982. Slow release dietary carbohydrate improves second meal tolerance. The American Journal of Clinical Nutrition 35, 1339-1346.

Jorgensen H, Lindberg JE and Andersson C 1997. Diurnal variation in the composition of ileal digesta and the ileal digestibilities of nutrients in growing pigs. Journal of the Science of Food and Agriculture 74, 244-250.

Kim B, Lindemann M, Cromwell G, Balfagon A and Agudelo J 2007. The correlation between passage rate of digesta and dry matter digestibility in various stages of swine. Livestock Science 109, 81-84.

Kyriazakis I and Emmans $G$ 1995. The voluntary feed intake of pigs given feeds based on wheat bran, dried citrus pulp and grass meal, in relation to measurements of feed bulk. British Journal of Nutrition 73, 191-207.

Lee B-H, Bello-Perez LA, Lin AH-M and Kim CY 2013. Importance of location of digestion and colonic fermentation of starch related to its quality. Cereal Chemistry 90, 335-343.

Le Goff G, Van Milgen J and Noblet J 2002. Influence of dietary fibre on digestive utilization and rate of passage in growing pigs, finishing pigs and adult sows. Animal Science 74, 503-515. 
Le Gall M, Warpechowski M, Jaguelin-Peyraud Y and Noblet J 2009. Influence of dietary fibre level and pelleting on the digestibility of energy and nutrients in growing pigs and adult sows. Animal 3, 352-359.

Lewis SJ and Heaton KW 1997. Increasing butyrate concentration in the distal colon by accelerating intestinal transit. Gut 41, 245-251.

Livesey $\mathrm{G}$ and Tagami $\mathrm{H}$ 2009. Interventions to lower the glycemic response to carbohydrate foods with a low-viscosity fiber (resistant maltodextrin): metaanalysis of randomized controlled trials. The American Journal of Clinical Nutrition 89, 114-125.

Mahasukhonthachat K, Sopade PA and Gidley MJ 2010. Kinetics of starch digestion in sorghum as affected by particle size. Journal of Food Engineering 96, 18-28.

Maljaars P, Peters HPF and Masclee AM 2007. Review article: the gastrointestinal tract: neuroendocrine regulation of satiety and food intake. Alimentary Pharmacology and Therapeutics 26 Suppl 2, 241-250.

Maljaars P, Peters HPF, Mela DJ and Masclee AAM 2008. Ileal brake: a sensible food target for appetite control. A review. Physiology \& Behavior 95, 271-281.

Mateos G, Martin F, Latorre M, Vicente B and Lazaro R 2006. Inclusion of oat hulls in diets for young pigs based on cooked maize or cooked rice. Animal Science 82, 57-63.

Muir JG, Yeow EG, Keogh J, Pizzey C, Bird AR, Sharpe K, O'Dea K and Macrae FA 2004. Combining wheat bran with resistant starch has more beneficial effects on fecal indexes than does wheat bran alone. The American Journal of Clinical Nutrition 79, 1020-1028.

Murphy KG and Bloom SR 2006. Gut hormones and the regulation of energy homeostasis. Nature 444, 854-859.

Nightingale J, Kamm M, Van der Sijp J, Ghatei M, Bloom S and Lennard-Jones J 1996. Gastrointestinal hormones in short bowel syndrome. Peptide YY may be the'colonic brake'to gastric emptying. Gut 39, 267-272.

Noblet J and Henry Y 1993. Energy evaluation systems for pig diets: a review. Livestock Production Science 36, 121-141.

Nyachoti C, Zijlstra R, De Lange C and Patience J 2004. Voluntary feed intake in growing-finishing pigs: a review of the main determining factors and potential approaches for accurate predictions. Canadian Journal of Animal Science 84, 549-566.

Phillips PA, Phillips PA, Young BA and McQuitty JB 1982. Liveweight, protein deposition and digestibility responses in growing pigs exposed to low temperature. Canadian Veterinary Journal 62, 95-108.

Potkins Z, Lawrence T and Thomlinson J 1991. Effects of structural and non-structural polysaccharides in the diet of the growing pig on gastric emptying rate and rate of passage of digesta to the terminal ileum and through the total gastrointestinal tract. British Journal of Nutrition 65, 391-413.

Powley TL and Phillips RJ 2004. Gastric satiation is volumetric, intestinal satiation is nutritive. Physiology \& Behavior $82,69-74$.

Ratanpaul V, Williams BA, Black JL and Gidley MJ 2018. Apparent amylase diffusion rates in milled cereal grains determined in vitro: potential relevance to digestion in the small intestine of pigs. Journal of Cereal Science 82 , 42-48.

Ritter RC 2004. Gastrointestinal mechanisms of satiation for food. Physiology \& Behavior 81, 249-273.

Rolls E 2007. Understanding the mechanisms of food intake and obesity. Obesity Reviews 8, 67-72.

Roura E, Koopmans S-J, Lallès J-P, Le Huerou-Luron I, De Jager N, Schuurman T and Val-Laillet D 2016. Critical review evaluating the pig as a model for human nutritional physiology. Nutrition Research Reviews 29, 60-90.

Saltiel AR and Kahn CR 2001. Insulin signalling and the regulation of glucose and lipid metabolism. Nature 414, 799-806.

Saqui-Salces M, Luo Z, Urriola PE, Kerr BJ and Shurson GC 2017. Effect of dietary fiber and diet particle size on nutrient digestibility and gastrointestinal secretory function in growing pigs. Journal of Animal Science 95, 2640-2648.

Scazzina F, Siebenhandl-Ehn S and Pellegrini N 2013. The effect of dietary fibre on reducing the glycaemic index of bread. British Journal of Nutrition 109, 1163-1174.

Schulze K 2006. Imaging and modelling of digestion in the stomach and the duodenum. Neurogastroenterology and Motility 18, 172-183.

Shin HS, Poppitt SD, McGill A-T, Lo K and Ingram J 2013. Foods for appetite control: can carbohydrates stimulate the ileal brake and enhance satiety? Obesity Research \& Clinical Practice, e23.

Solà-Oriol D, Torrallardona D and Gasa J 2010. Role of dietary fibre source and meal size on the ileal transit of digesta in growing pigs. Livestock Science 133, 67-69.

Stanogias $G$ and Pearcet $G$ 1985. The digestion of fibre by pigs. British Journal of Nutrition 53, 513-530.

Taylor JRN, Emmambux MN and Kruger J 2015. Developments in modulating glycaemic response in starchy cereal foods. Starch-Starke 67, 79-89.

Theil PK, Jorgensen H, Serena A, Hendrickson J and Knudsen KEB 2011. Products deriving from microbial fermentation are linked to insulinaemic response in pigs fed breads prepared from whole-wheat grain and wheat and rye ingredients. British Journal of Nutrition 105, 373-383.

van Avesaat M, Troost F, Ripken D, Hendriks $H$ and Masclee A 2015. lleal brake activation: macronutrient-specific effects on eating behavior? International Journal of Obesity 39, 235-243.

Vicente B, Valencia D, Pérez-Serrano M, Lázaro R and Mateos $G$ 2008. The effects of feeding rice in substitution of corn and the degree of starch gelatinization of rice on the digestibility of dietary components and productive performance of young pigs. Journal of Animal Science 86, 119-126.

Wilfart A, Montagne L, Simmins H, Noblet J and Milgen Jv 2007. Digesta transit in different segments of the gastrointestinal tract of pigs as affected by insoluble fibre supplied by wheat bran. British Journal of Nutrition 98, 54-62.

Wren AM and Bloom SR 2007. Gut hormones and appetite control. Gastroenterology 132, 2116-2130. 